\title{
Lip Print Characteristics in Anatolian Population: Baskent University Sample
}

\author{
Can Pelin11, Hale Oktem ${ }^{1}$, Ayla Kurkcuoglu1, Hulya Olmus² \\ ${ }^{1}$ Department of Anatomy, Faculty of Medicine, Baskent University, Ankara, Turkey \\ ${ }^{2}$ Department of Istatistics, Faculty of Science, Gazi University, Ankara, Turkey \\ Email: ^haleoktem@gmail.com
}

How to cite this paper: Pelin, C., Oktem, H., Kurkcuoglu, A. and Olmus, H. (2019) Lip Print Characteristics in Anatolian Population: Baskent University Sample. Open Access Library Journal, 6: e5171. https://doi.org/10.4236/oalib.1105171

Received: January 7, 2019

Accepted: January 22, 2019

Published: January 25, 2019

Copyright @ 2019 by author(s) and Open Access Library Inc.

This work is licensed under the Creative Commons Attribution International License (CC BY 4.0).

http://creativecommons.org/licenses/by/4.0/

(c) (i) Open Access

\begin{abstract}
Background: Identification is of importance for any crime investigation. Among several other methods, lip prints, if available, should also be evaluated to point out the relationship between the individual and the committed crimes. Lip print evaluation is known as "cheiloscopy" and important for forensic anthropologists in identification process since they are unique for each individual as fingerprints. Sex estimation is from lip print. Methods: 143 male and 291 female, a total of 434 students, were participated to the study. Lip prints were taken from each individual by using a dark colored lipstick and cellophane tape and fixed on a white sheet of paper. Lip prints were evaluated after separated into six quadrants (upper lip and lower were divided into three quadrants). The print patterns in each quadrant were classified according to Tsuchihashi method. Results: Sex estimation was done by using binary logistic regression analysis. Forked grooves both in right and left upper quadrants and reticular grooves in the upper middle quadrant were the most commonly observed lip print patterns. The lower lip forked grooves in both lateral quadrants and complete vertical grooves in the middle quadrant were the most commonly observed patterns both in males and females. Statistical analysis indicated that by binary logistic regression equations sex could be estimated with an accuracy of $72.6 \%$. Lip prints give good predictability in determining sex, but cannot be used as the key tool in sex identification.
\end{abstract}

\section{Subject Area}

Anatomy \& Physiology

\section{Keywords}

Cheiloscopy, Identification, Forensic Medicine 


\section{Introduction}

Estimating a person's individuality is without doubt important in forensic cases. An accurate identification is required not only to recognize dead persons and decomposing and mutilated bodies, but also to determine missing persons or the ones related with a committed crime, but hiding themselves [1] [2] [3].

In any crime scene investigation all the evidences related with the identity of the offender should be evaluated in details. In such cases comparison of fingerprints or DNA samples isolated from hair, skin debris, blood or semen spots available from the crime scene are the most reliable methods [4]. However, in some instances techniques other than the above mentioned ones should also be used. Though lip prints are not evaluated for identification frequently in the forensic field, they should be taken into consideration since they give accurate estimate for the identity of an individual.

Studying lip prints for identification in the forensic field is known as cheiloscopy. Cheiloscopy is a technique used for identification of humans in the field of forensic anthropology based on characteristic pattern of the lines appearing on the red part of the lips [5] [6]. Like finger prints and palatal rugae, lip prints also represent soft tissue pattern and are unique for the individual. Lip prints are as reliable as finger prints in estimating the identity of an individual. However, contrary to finger prints, lip prints are highly similar in homozygote twins [5] [7]. On the other hand, Szuki and Tsuchihashi in their study on homozygote twins reporte that even though lip prints are highly similar there are still some differences caused by the different genes inherited from the parents [8].

Lip prints could be detacted as early as in the sixth week of the intrauterine life and do not change during the life of a person, resisting many afflictions [4] [9]. Even after undergoing severe alterations caused by trauma, inflammation diseases such as herpes can be recovered [10]. Lip print patterns were first determined by Fischer in 1902 [9]. In the forensic field they were evaluated by Sir Edmund Locard for identification for the first time [7]. Later various researches have been done emphasizing the importance of cheiloscopy in forensic anthropology. Lip print patterns were evaluated to estimate sex and ethnical origin of an individual [5] [6] [7]. They may give some information about the job or the habitudes of an individual [7]. There are also some articles indicating the correlation between lip print patterns and blood groups [11] [12].

Lip prints may be obtained at the crime scene especially from glass surfaces, napkins, paper sheets, clothes, and cigarette buds, from the ropes used to bind the victims or even from the skin of the victim [9] [13]. Cheiloscopy without doubt supplies evidence to reveal the affiliation between the crime and the criminal especially in complex cases in which more than one suspects is present.

Lip prints have been evaluated in the forensic context by several authors in various populations. However, those studies relying on lip prints for sex estimation are limited [7] [14]. This is a preliminary study to determine the lip print characteristics of Anatolian population and to evaluate the accuracy of cheilos- 
copy on sex estimation.

\section{Materials and Methods}

The study was conducted on 143 male and 291 female, a total of 434 individuals. All the subjects were the students of Başkent University. Mean age was $21.17 \pm$ 2.37 for males and $20.70 \pm 2.67$ for females.

All the subjects were first wanted to clean their lips by using a nonirritant antiseptic solution. After the lips get dried a thin film of a dark bright colored, non-glossy and nonpermanent lipstick was applied with a single stock on the vermillion border. The subjects were made to rub both the lips to spread the lipstick homogenously. Lip prints were then recorded by applying a transparent cellophane tape to each lip. Later the tape was applied to a white sheet of paper as shown in Figure 1. The procedure was repeated three times and the best print without any artifacts was examined.

Each print on the white sheet of paper was first divided into three quadrants as two lateral and one middle quadrant shown in Figure 1 and the prints on each quadrant were then evaluated by using a magnifying lens.

Lip prints types were determined according to Tsuchihashi classification [8].

Type 1: Vertical grooves running across the entire lip;

Type 2: Vertical grooves but not running across the entire lip (intermittent groves);

Type 3: Forked grooves;

Type 4: Intersected grooves;

Type 5: Reticular grooves;

Type 6: Others.

In the quadrants containing more than one lip print type the predominant one was taken into consideration.

Distribution of lip print patterns related with sexes was evaluated using Chi-square and Likelihood Ratio tests. For sex estimation multiple stepwise binary logistic regression analysis was used.

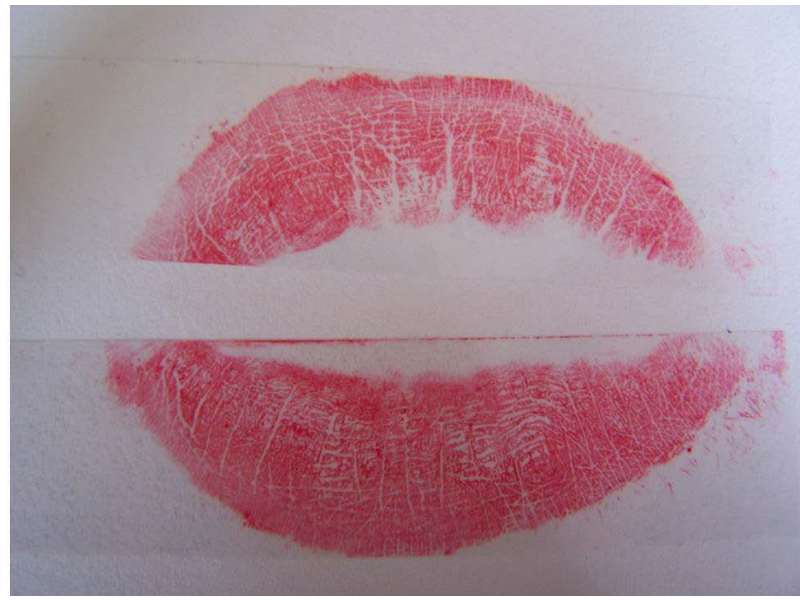

Figure 1. An example of lip print grooves. 
The data was analyzed using SPSS statistical package 17.0 (SPSS Ver. 17.0, Chicago, IL, USA).

The study with the project number KA14/16 was approved by Baskent University Institutional Review Board and Ethics Committee.

\section{Results}

Distribution of lip print types on upper and lower lips was reported in Table 1 and Table 2. A significant relationship was determined between lip print characteristics and sex for the upper lip. On the lateral quadrants the most predominant pattern was forked grooves (Type 3) both in males and females. Two proportion $\mathrm{z}$-test indicates that on the upper lateral quadrants the predominance of the forked grooves was significantly higher in male subjects when compared with females $(p<0.001)$. Forked groove type was followed by vertical grooves in males and by intersecting grooves in females. No print type other than the mentioned five types has been observed on the upper lateral quadrants in male subjects. In females the most rarely observed print type was intermittent grooves on the right upper lateral quadrant and the print types other than the mentioned forms on the left upper quadrant. On the upper middle quadrant the most predominant lip print form was reticular type for both sexes, and this was followed

Table 1. Distribution of print types on the upper lip according to sex.

\begin{tabular}{cccccccccc}
\hline & \multicolumn{3}{c}{ Right } & \multicolumn{3}{c}{ Middle } & & \multicolumn{2}{c}{ Left } \\
\hline & Male & Female & $\mathrm{p}$ & Male & Female & $\mathrm{p}$ & Female & Male & $\mathrm{p}$ \\
\hline Vertical grooves & 26.6 & 14.8 & & 16.1 & 7.9 & & 21.0 & 15.1 & \\
$\begin{array}{c}\text { Intermittent vertical } \\
\text { grooves }\end{array}$ & 0.7 & 5.5 & & 2.8 & 3.4 & & 2.8 & 4.8 & \\
Forked grooves & 53.8 & 38.1 & $<0.001$ & 22.4 & 17.9 & $<0.05$ & 64.3 & 49.1 & $<0.001$ \\
Intersecting grooves & 9.1 & 25.8 & & 4.2 & 10.3 & & 9.1 & 21.6 & \\
Reticular grooves & 9.8 & 8.9 & & 50.3 & 57 & & 2.8 & 6.5 & \\
Others & 0.0 & 6.9 & & 4.2 & 3.4 & & 0.0 & 2.7
\end{tabular}

Table 2. Distribution of print types on the lower lip according to sex.

\begin{tabular}{cccccccccc}
\hline & \multicolumn{3}{c}{ Right } & \multicolumn{3}{c}{ Middle } & & \multicolumn{2}{c}{ Left } \\
\hline & Male & Female & $\mathrm{p}$ & Male & Female & $\mathrm{p}$ & Female & Male & $\mathrm{p}$ \\
\hline $\begin{array}{c}\text { Vertical grooves } \\
\text { Intermittent vertical }\end{array}$ & 14.0 & 13.1 & & 61.5 & 45.4 & & 5.6 & 7.9 & \\
$\quad 6.3$ & 2.1 & & 8.4 & 6.5 & & 3.5 & 3.1 & \\
grooves & & & & & & & & & \\
Forked grooves & 74.1 & 67.7 & $<0.001$ & 15.4 & 23.7 & $<0.05$ & 72.7 & 65.6 & 0.710 \\
$\begin{array}{c}\text { Intersecting grooves } \\
\text { Reticular grooves }\end{array}$ & 4.9 & 12.7 & & 1.4 & 4.1 & & 14.7 & 17.9 & \\
Others & 0.7 & 2.4 & 2.1 & & 2.1 & 2.4 & & 3.5 & 3.1 \\
\hline
\end{tabular}


by forked grooves. No statistically significant sex difference was found related with reticular and forked lip print pattern. On the other hand on the lateral quadrants forked type lip prints were significantly higher in male subjects $(\mathrm{p}<$ 0.001). The most rarely observed lip print type on the upper middle quadrant was the intermittent vertical lines in both sexes.

When the print pattern of the lower lip was evaluated similar to the upper lip on the lateral quadrants the most prevalent print type was forked lines in both sexes. However no significant difference was observed between the two sexes ( $\mathrm{p}$ $<0.01)$. On the right lower quadrant, forked lines were followed by vertical grooves, and on the left lower quadrant by intersecting grooves both in male and female subjects. Different from the upper middle quadrant the most predominant lip print pattern on the lower middle quadrant was vertical grooves, and its incidence was higher in males $(\mathrm{p}<0.01)$. Vertical grooves observed on the lower middle quadrant were followed by forked grooves. On the lower middle quadrant significant sex difference was observed for vertical, forked, intersecting and reticular type lip prints. While vertical grooves were significantly higher in males, forked, intersecting and reticular types were higher in females. On the left lower quadrant no sex difference was observed for all lip print types. Contrary to upper middle quadrant the incidence of forked grooves is significantly higher in females $(\mathrm{p}<0.01)$.

Binary logistic regression analysis indicated that print pattern on upper right quadrant, upper and lower middle quadrants were the most determining criteria for sex estimation (as demonstrated in Table 3 ).

Table 3 presented that the odds of observing intersecting grooves on the upper right lateral quadrant was 3.262 times, and interrupting grooves was 10.617 times higher in female subjects when compared with males. On the upper middle quadrant the odds of observing intersecting grooves was 5.156 times higher in females than males. On the lower middle quadrant the odds of observing forked grooves was 2.366 times and reticular type grooves was 2.893 times higher in females.

Logistic regression equation calculated depending on the data of the present study is

$$
Y=0.710+1.82 X 1+2.362 X 2+1.640 X 3+0.861 X 4+1.062 X 5
$$

$X 1$ : Upper right intersecting grooves;

$X 2$ : Upper right intermittent grooves;

$X 3$ : Upper middle intersecting grooves;

$X 4$ : Lower middle forked grooves;

$X 5$ : Lower middle reticular grooves.

For the all known male subjects in the sample true positive rate was 0.462 . In other words among all known males only $46.2 \%$ were predicted correctly. On the other hand among all known female subjects $85.6 \%$ were predicted correctly (as demonstrated in Table 4). The statistical analysis indicates that the accuracy of the calculated binary logistic regression analysis is 0.726 . However the probability of estimating female subjects correctly is higher when compared with males. 
Table 3. Significant variables in logistic regression model.

\begin{tabular}{cccccc}
\hline Quadrant & $\beta$ & SE & Wald & $\mathrm{p}$ & OR \\
\hline Constant & 0.710 & 0.102 & 48.4 & 0.001 & 2.035 \\
Upper right (intersecting grooves) & 1.182 & 0.430 & 7.564 & 0.006 & 3.262 \\
Upper right (intermittent grooves) & 2.362 & 1.086 & 4.733 & 0.030 & 10.617 \\
Upper middle (intersecting grooves) & 1.640 & 0.604 & 7.372 & 0.007 & 5.156 \\
Lower middle (forked grooves) & 0.861 & 0.323 & 7.115 & 0.008 & 2.366 \\
Lower middle (reticular grooves) & 1.062 & 0.362 & 8.634 & 0.003 & 2.893 \\
\hline
\end{tabular}

Table 4. Classification table.

\begin{tabular}{cccc}
\hline & \multicolumn{2}{c}{ Predicted sex } & Percentage correct \\
\hline Sex & Male & Female & \\
Male & 66 & 77 & 46.2 \\
Female & 42 & 249 & 85.76 \\
Overall persentage & & & 72.6 \\
\hline
\end{tabular}

\section{Discussion}

Lip print patterns of two different individuals look like quite similar the site and the number of the grooves on the lips. However their intersection points, branching pattern and reticulation are certainly different from one another [2]. In the studies on cheiloscopy lip prints were reported to be unique and accepted as valuable clue for identification [3] [9] [15] [16]. Even though lip prints are available in crime scenes on various surfaces including biological ones they are not effectively evaluated in crime scene investigations.

Up to date lip print patterns have been studied in different aspects; their relationship with genetic disorders, blood groups, fingerprints and gender difference has been evaluated [2] [17] [18] [19] [20]. In the present study lip print pattern of Anatolian population and their reliability in forensic anthropology for sex estimation was evaluated.

Vats et al. studied lip print patterns on North Indian populations and reported that Brahmins exhibit the maximum prevalence of the print type in which two or more than two print pattern take place. However both in males and females this was followed by forked grooves. In Jats, another ethnic group living in India, the most frequently observed lip print pattern in males was the reticular form, and mixed pattern in females' pattern. However the mixed pattern observed in females was followed by reticular form [21]. Kumar et al. in their study on Indian Pondicherry population the highest percentage of occurrence was shown by forked grooves in females and by intersecting grooves in males [9]. Gondivkar et al. in their study on 140 Indians reported that forked grooves was the most frequently observed pattern on both lips both in males and females [17]. In another study on Indian population lip print patterns of Korela and Manipuri popula- 
tions were evaluated comparatively. It has been observed that the maximum prevalence is of vertical grooves for the both ethnic groups. However frequency of observing reticular form in males and vertical form in females were relatively higher in Korela population when compared with Manipuri population. On the other hand in Manipuri males' reticular grooves, and in Manipuri females vertical or intermittent vertical grooves were relatively higher [4]. When the lip print patterns of various ethnic groups living in India were evaluated it was observed that some patterns are common in all groups. However some patterns those were frequently observed in one group were extremely lower in another one. These findings indicate that lip print patterns are specific to populations. However forked grooves and reticuler form are the most commonly observed lip print types in Indian population [21]. Karki et al. in their study on 140 students of medicine in Kathmandu reported that maximum occurrence is shown by forked lines [22]. Ragab et al. indicated that the prevalence of vertical grooves was the highest in Egyptian population for both sexes, especially on lower middle quadrant [2]. In a study on Portuguese population the most commonly observed print pattern was forked grooves [10]. In the present study similar with Portuguese population forked grooves have the highest incidence. In another study on a large sample representing Almadinah Almonawarah population of Saudi Arabia similar with the present study print pattern was evaluated after the lips had been separated into six quadrants. However instead of Tsuchihashi method lip prints were determined in ten groups. The most predominant print types were horizontal grooves and forked groves accompanied with other print types both for males and females. Horizontal lines accompanied with other print types were commonly observed on the upper middle quadrant and the forked grooves were on the right lateral quadrant [23]. In the present study on Anatolian population forked grooves have the highest prevalence, however on the lateral quadrants.

Left lateral lower quadrant does not have any discriminative specificity for sex estimation. Pamavathi et al. have reported that print pattern of the upper lip is of importance for determining sex, however lower lip is not [24]. Different from the present study in Pamavathi's study doted and mixed print forms gain importance for sex estimation; doted and reticular print forms on the upper middle quadrant are significantly higher in males and mixed print type was in females. Accuracy of the equations by Costa was $72 \%$ for female and $64 \%$ for males. Of 25 males eight were estimated as females [10]. In the present study of 143 males 77 were estimated as females. True positive rate of the equation calculated in the present study (46.2\%) was quite lower than that of Costa's. On Indian population Sharma evaluated the print patterns on the middle quadrants and reported that vertical grooves and interrupted vertical grooves have highest prevalence in females and reticular form in males [19]. In the present study on the upper middle quadrant the most commonly observed lip print type was reticular form for both sexes and vertical grooves on the lower middle quadrant. However inci- 
dence of observing vertical grooves on the lower middle quadrant was higher in males when compared with female subjects. In most of the studies on cheiloscopy it was reported that sex could accurately be estimated depending on lip print patterns [17] [18] [19] [20]. However, the dominance of print patterns types varies among populations. On the other hand contrary to most of the studies referred in the literature there are some researches emphasizing the inaccuracy of cheiloscopy for estimating sex [2].

\section{Conclusion}

The results of the present study indicate that the most predominant lip print type in Anatolian population is forked grooves. Binary logistic regression equations obtained in the present study depending on lip print patterns give good predictability in determining sex, especially for female individuals. However, they cannot be used as the key tool in sex identification. But lip prints may hold as a promising tool along with other modes to recognize the sex of an individual.

\section{Conflicts of Interest}

There is no conflict of interest.

\section{References}

[1] Kanchan, T. and Krishan, K. (2011) Anthropometry of Hand in Sex Determination of Dismembered Remains-A Review of Literature. Journal of Forensic and Legal Medicine, 18, 14-17. https://doi.org/10.1016/j.jflm.2010.11.013

[2] Ragab, A.R., El-Dakroory, S.A. and Rahman, R.H. (2013) Characteristic Patterns of Lip Prints in Egyptian Population Sample at Dakahlia Governorate. International Journal of Legal Medicine, 127, 521-527. https://doi.org/10.1007/s00414-012-0784-5

[3] Saraswathi, T.R., Mishara, G. and Ranganathan, K. (2009) Study of Lip Prints. Journal of Forensic Dental Sciences, 1, 28-31. https://doi.org/10.4103/0974-2948.50885

[4] Koneru, A., Surekha, R., Nellithady, G.S., Vanishree, M., Ramesh, D. and Patil, R.S. (2013) Comparison of Lip Prints in Two Different Populations of India: Reflections Based on a Preliminary Examination. Journal of Forensic Dental Sciences, 5, 11-15. https://doi.org/10.4103/0975-1475.114543

[5] Prabhu, R.V., Dinakar, A.D., Prabhu, A.D. and Rao, P.K. (2012) Cheiloscopy: Revisited. Journal of Forensic Dental Sciences, 4, 47-52. https://doi.org/10.4103/0975-1475.99167

[6] Prabhu, R.V., Dinkar, A. and Prabhu, V. (2012) A Study of Lip Pattern in Goan Dental Students-A Digital Approach. Journal of Forensic and Legal Medicine, 19, 390-395. https://doi.org/10.1016/j.jflm.2012.04.012

[7] Kautilya, V., Bodkha, P. and Rajamohan, N. (2013) Efficacy of Cheiloscopy in Determination of Sex among South Indians. Journal of Clinical and Diagnostic Research, 7, 2193-2196. https://doi.org/10.7860/JCDR/2013/5371.3468

[8] Suzuki, K. and Tsuchihashi, Y. (1970) New Attempt of Personal Identification by Means of Lip Print. Journal of the Indian Dental Association, 42, 8-9.

[9] Kumar, G.S., Vazhavendhan, N. and Vendhan, P. (2012) A Study of Lip Prints among Pondicherry Population. Journal of Forensic Dental Sciences, 4, 84-87. 
https://doi.org/10.4103/0975-1475.109894

[10] Costa, V.A. and Caldas, I.M. (2012) Morphological Patterns of Lip Prints in a Portuguesa Population: A Preliminary Analysis. Journal of Forensic Sciences, 57, 1318-1322. https://doi.org/10.1111/j.1556-4029.2012.02118.x

[11] Bharadwaja, A., Saraswat, P.K., Aggarwal, S.K., Banerji, P. and Bharadwaja, S. (2004) Pattern of Finger-Prints in Different ABO Blood Groups. Journal of Indian Academy of Forensic Medicine, 26, 6-9.

[12] Telagi, N., Mujib, A., Spoorthi, B. and Naik, R. (2011) Cheiloscopy and Its Patterns in Comparison with ABO Blood Groups. Journal of Forensic Dental Sciences, 3, 77-80. https://doi.org/10.4103/0975-1475.92150

[13] Kasprzak, J. (1990) Possibilities of Cheiloscopy. Forensic Science International, 46, 145-151. https://doi.org/10.1016/0379-0738(90)90154-Q

[14] Randhawa, K., Narang, R.S. and Arora, P.C. (2011) Study of the Effect of Age Changes on Lip Print Pattern and Its Reliability in Sex Determination. Journal of Forensic Odonto-Stomatology, 29, 45-51.

[15] Alverez Segui, M., Miquel Feucht, M., Castello Ponce, A. and Verdu Pascual, F. (2000) The Stability of Lip Pattern Characteristics over Time. Forensic Science International, 112, 41-47.

[16] Ball, J. (2002) The Currents Status of Lip Prints and Their Use for Identification. Journal of Forensic Odonto-Stomatology, 20, 43-46.

[17] Gondivkar, S.M., Indurkar, A., Degwekar, S. and Bhowate, R. (2009) Cheiloscopy for Sex Determination. Journal of Forensic Dental Sciences, 1, 56-60. https://doi.org/10.4103/0974-2948.60374

[18] Patel, S., Ish Paul, S., Madhusudan, A.S., Gayathri, R. and Sowmya, G.V. (2010) A Study of Lip Prints in Relation to Gender, Family and Blood Group. International Journal of Oral and Maxillofacial Pathology, 1, 4-7.

[19] Sharma, P., Saxena, S. and Rathod, V. (2010) The Study of Lip Prints in Sex Identification. Journal of Forensic Dental Sciences, 1, 24-27.

https://doi.org/10.4103/0974-2948.50884

[20] Vahanwala, S.P., Nayak, C.D. and Pagare, S.S. (2005) The Study of Lip Prints as Aid for Sex Determination. Medico-Legal Update, 5, 93-98.

[21] Vats, Y., Dhall, J.K. and Kapoor, A.K. (2012) Gender Variation in Morphological Patterns of Lip Prints among Some North Indian Populations. Journal of Forensic Dental Sciences, 4, 19-23. https://doi.org/10.4103/0975-1475.99155

[22] Karki, R.K. (2012) Lip Prints: An Identification Aid. Kathmandu University Medical Journal (KUM), 10, 55-57.

[23] El Domiaty, M.A., Al-gaidi, S.A., Elayat, A.A., Safwat, M.D. and Galal, S.A. (2010) Morphological Patterns of Lip Prints in Saudi Arabia at Almadinah Almonawarah Province. Forensic Science International, 200, 179. https://doi.org/10.1016/j.forsciint.2010.03.042

[24] Pamavathi, B.N., Makkad, R.S., Rajan, S.Y. and Kolli, G.K. (2013) Gender Determination Using Cheiloscopy. Journal of Forensic Dental Sciences, 5, 123-128. https://doi.org/10.4103/0975-1475.119780 